\title{
Short term measurements of indoor air quality when using the home office in Norway
}

\author{
Maria Justo Alonso ${ }^{1}{ }^{*}$, Rikke Bramming Jørgensen ${ }^{2}$,Hans Martin Mathisen ${ }^{1}$, \\ ${ }^{1}$ Norwegian University of Science and Technology, Energy and Process Engineering Department, 7491 Trondheim, Norway \\ ${ }^{2}$ Norwegian University of Science and Technology, Industrial Economics and Technology Management Department, 7491 \\ Trondheim, Norway
}

\begin{abstract}
In 2020, due to the outbreak of COVID-19 many workers have been sent home to avoid the sickness spread. As a result, rooms that otherwise had domestic use, living rooms or bedrooms, have become offices. This change has happened in many houses without improving the ventilation systems. In many cases, the rooms were overcrowded, and no attention was paid to ventilation. Thus, this study collects measurements of one to two weeks in different home offices. Measurements were taken in home offices used by one or more occupants. These home offices were designed as bedrooms and living rooms with and without separation from the kitchen. During the pandemic they are used as offices during working hours and as designed otherwise. One or more occupants shared the rooms. Natural and mechanically ventilated and older and newer home offices were studied. Winter measurements of $\mathrm{CO}_{2}$, temperature, relative humidity, particulate matter, formaldehyde and TVOC were collected via low-cost sensors. The sensors were placed on the working space in front of the user to map the exposure to pollutants. The results show an analysis of the concentration of pollutants close to the breathed air. Some users were smart, remembering the aeration, whereas others were exposed to high concentrations of $\mathrm{CO}_{2}$ and other pollutants sometimes higher than the health-based thresholds
\end{abstract}

\section{Introduction}

The coronavirus disease 2019 (COVID-19) is caused by the transmission of severe acute respiratory syndrome coronavirus 2 (SARS-CoV-2). On the auspices of the outbreak of the COVID-19 pandemic in March 2020 workers were requested to work from home from one day to the other. Rooms that were designed for domestic use were suddenly transformed into home offices. Some people used the kitchen bench, some people the living room and some bedrooms. Some people had at least the reglementary area per office workplace of $6 \mathrm{~m}^{2}[1]$, some did not. Anyhow, there was too much risk for COVID contamination and people had to work from home whenever possible. However, now is December 2020 and many of us keep on working from home as the risk of contamination is still high.

The Norwegian authorities published a guide that provides advice on how workplaces should be arranged to reduce the risk of infection in May [2]. This document does not specify any further information about ventilation. The Norwegian Labour Inspection Authority specifies that "To ensure that the employee's safety, health and welfare are safeguarded, the employer must, as far as practicable, ensure that the working conditions are fully justifiable. This applies, among other things, to the workplace, work equipment and the indoor environment not causing unfortunate physical strain"[3]. This rule of behavior is not very

\footnotetext{
* Corresponding author: maria.j.alonso@ntnu.no
}

specific. For this article, we assume that the home office should meet the criteria defined in the building codes [4] and in the occupational health and public health legislation [5], [6] as humans are the same and the effect of pollutants on health is the same at home or the office.

Owing to recommendations in [3], it was a general move in many companies to provide computers, screens and chairs to satisfy the ergonomic challenge of moving to the home office. However, ventilation or indoor air quality (IAQ) was not followed up as closely. This article intends to map the indoor air quality that a sample of users is exposed to when working from home. Measurements taken during one to two weeks show that more attention should be drawn towards the IAQ and probably employers should give some recommendations and requirements to the home office users.

\section{Methods}

This study is a field study realized in December 2020 when home office use was still recommended in Norway. Eligibility criteria required individuals to be working from home at least four of the seven days of the week. The participants of this study were recruited from the academic environment of Trondheim, Norway. A sample of eleven houses has been selected for collecting the measurements. Such a small sample was chosen because of the restricted number of available sensors. There are several instruments with different accuracy 
for measuring the IAQ. We used low-cost sensors as these could be used to monitor the IAQ and not represent a huge economic investment. More information about the employed sensor and their calibration can be found in [7] (under publication).

The sensor was placed in the working table next to the keyboard to represent as much as possible the breathed air (note that these measurements would not be sufficient to represent the whole room as the mixing of the air or any other considerations about air distribution in the room have not been studied. These measurements only intend to represent the air breathed by the home office user).

To quantify the normal IAQ that the employees were breathing, the participants were asked to behave as normally as possible and not to change their practices regarding window opening. To know their habits regarding ventilation, all participants were sent an anonymized questionnaire. To control for bias regarding outdoor air, at least three houses were measured simultaneously in the same area of the city. Data management and analysis were performed using $\mathrm{R}$ studio Version 1.3.959.

Once the samples were extracted, the feedback was given to the users in the form of recommendations regarding window opening.

In observational studies, there is a potential for bias from the users over opening the windows as they feel "observed by the sensors". A longer measurement period would have been better to reduce this bias. The small size of the dataset with all the users coming from the same population of engineering may be affecting the results as well. Thus, further data collection is required to determine exactly the IAQ representative for Norwegian home offices. Table 1 presents the home offices where the results were collected results.

Table 1. Shows the sample where measurements are collected. The nomenclature used is described below. Type: Type of building where the measurements are performed, Bdg. Loc: Building location the city, SDH: Semi-detached house, SFH: single-family house, A: Apartment, B: Basement, Ba: Bathroom, K: Kitchen, S: Staircase, B: Bedroom, LR: Living room, CC: City center, SNF: Suburban non-forested area, SF: suburban forested area, NV natural ventilation, EV: Exhaust ventilation, MBV: Mechanical balanced ventilation.

\begin{tabular}{|c|c|c|c|l|c|c|}
\hline ID & Type & Floor & $\begin{array}{c}\text { Area } \\
\left(\mathrm{m}^{2}\right)\end{array}$ & $\begin{array}{l}\text { Linked } \\
\text { room }\end{array}$ & $\begin{array}{c}\text { Bdg. } \\
\text { loc }\end{array}$ & $\begin{array}{c}\text { Ventilati } \\
\text { on }\end{array}$ \\
\hline 1a & SFH & $2^{\text {nd }}$ & 12 & LR, B & CC & NV \\
\hline 1b & A & $3^{\text {rd }}$ & 9.8 & Ba & CC & NV+EV \\
\hline 1c & A & $2^{\text {nd }}$ & 48 & LR & CC & NV+EV \\
\hline 1d & SDH & $3^{\text {rd }}$ & 15 & S & SNF & MBV \\
\hline 2a & SDH & $2^{\text {nd }}$ & 5 & B & SNF & NV \\
\hline 2b & SFH & B & 4.5 & LR,B,K & SF & NV+EV \\
\hline 2c & A & $2^{\text {nd }}$ & 40.4 & LR,K & SNF & NV \\
\hline 2d & A & $1^{\text {st }}$ & 15 & LR,B,K & CC & NV \\
\hline $3 \mathrm{a}$ & SDH & B & 32 & LR,B,K & SNF & NV \\
\hline $3 \mathrm{~b}$ & SFH & B & 4.5 & LR,B & SF & NV+EV \\
\hline $3 \mathrm{c}$ & SDH & $1^{\text {st }}$ & 10.5 & B & SF & NV \\
\hline
\end{tabular}

$36 \%$ of the measurements are done in single-family houses, $36 \%$ in apartments and $28 \%$ in semi-detached houses. $28 \%$ of the rooms are in basements, $18 \%$ on the first floor, $36 \%$ on the second floor and $18 \%$ on the third floor. $54 \%$ of the rooms are used for at least two functions in addition to the home office, indeed only 45 $\%$ were designed as domestic offices. There is only one building that has mechanical balanced ventilation. $36 \%$ of the offices are placed so close to the bathroom that their ventilation is affected by its extraction. Other $36 \%$ have an opening to the kitchen and the extraction via the kitchen hood would influence the pollutants. However, in these cases, the kitchen activities will as well affect the pollutant concentration.

Measurements are done in one house of 1900 , one house from 2018 and the rest of the houses are constructed in the period from 1950 to 1970 . Among the latter, $45 \%$ have undergone renovations such as newer windows and/or tighter envelope.

\subsection{Outdoor conditions during measurements}

Measurements were performed from the eighth of December to the $31^{\text {st }}$. During this period, the wind velocity was on average $2 \mathrm{~m} / \mathrm{s}$ with a maximum of 9.4 $\mathrm{m} / \mathrm{s}$ blowing mostly from the South. A summary of the measurements is shown in Figure 1.

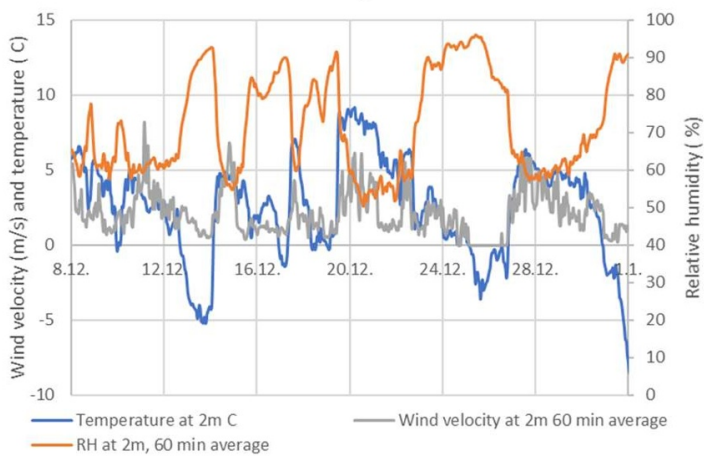

Figure 1. Summary of outdoor conditions during the measurements

\section{Results}

The results are presented as weekly graphs of the measurements:

- Thirty minutes averages of formaldehyde in $\mu \mathrm{g} / \mathrm{m}^{3}$.

- Continuous measurements of Total Volatile Organic Compounds (TVOC) in $\mu \mathrm{g} / \mathrm{m}^{3}$.

- Daily averages of $\mathrm{PM}_{2.5}$ in $\mu \mathrm{g} / \mathrm{m}^{3}$.

- Temperatures in ${ }^{\circ} \mathrm{C}$.

- Relative humidity in \%.

- $\mathrm{CO}_{2}$ concentration in ppm.

The horizontal green lines in Figures 2, 3 and 4 represent existing maximum thresholds defined by the national or international authorities and the purple represent the recommendations by the Norwegian authorities. Following this:

- The threshold for Formaldehyde is $100 \mu \mathrm{g} / \mathrm{m}^{3}$ according to [8] 


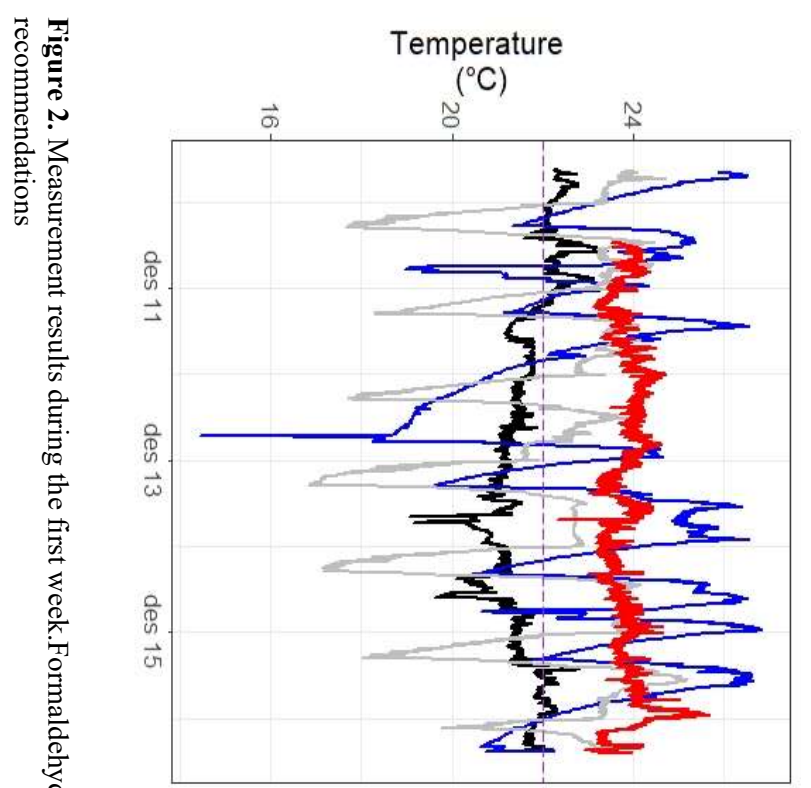

Relative humidity

(\%)

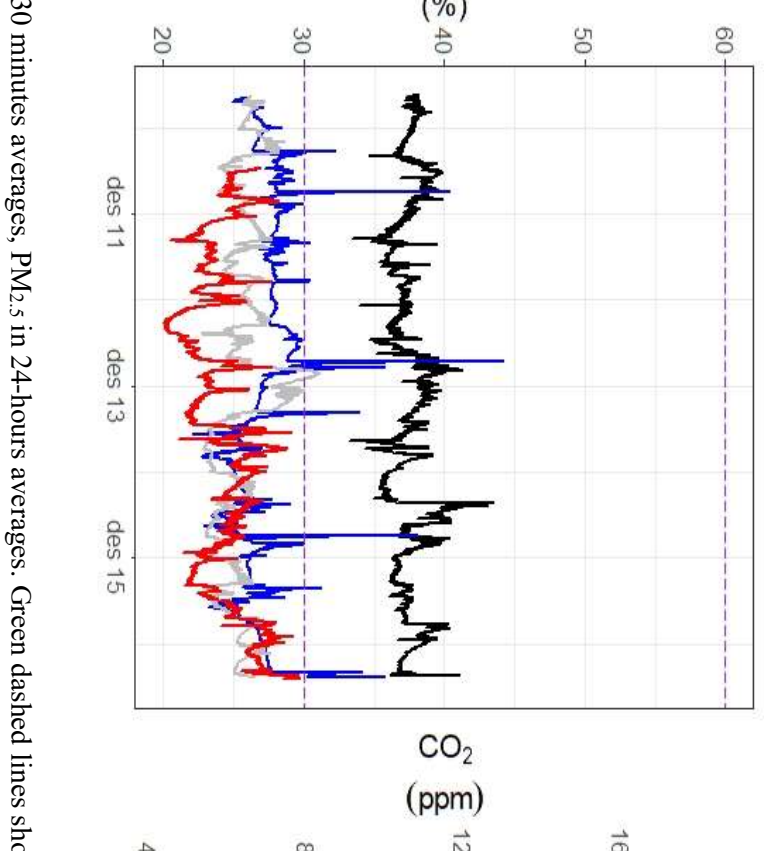

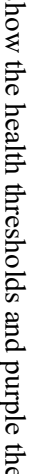
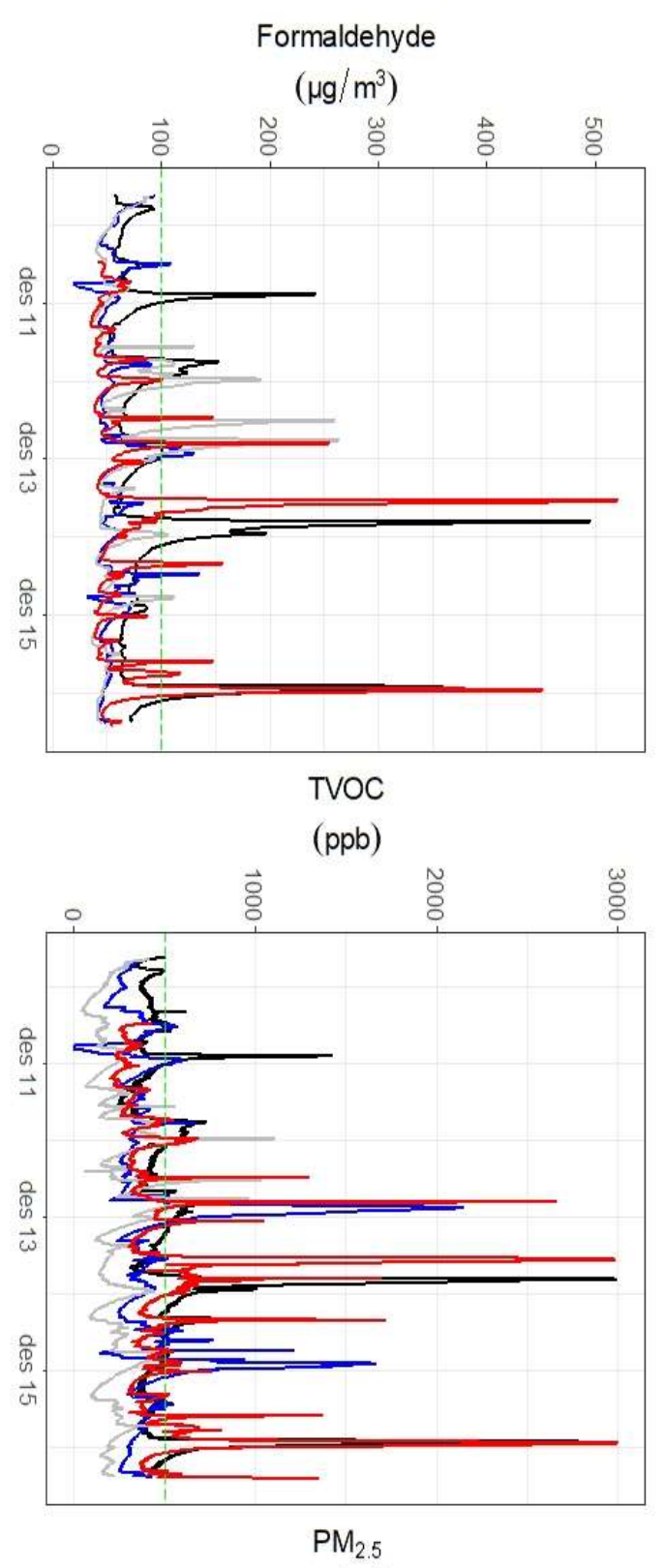

$\left(\mu \mathrm{g} / \mathrm{m}^{3}\right)$

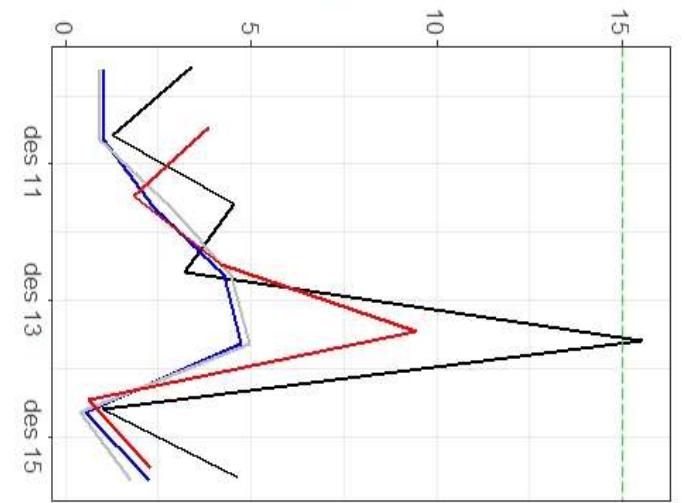

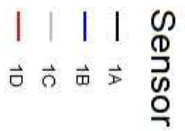



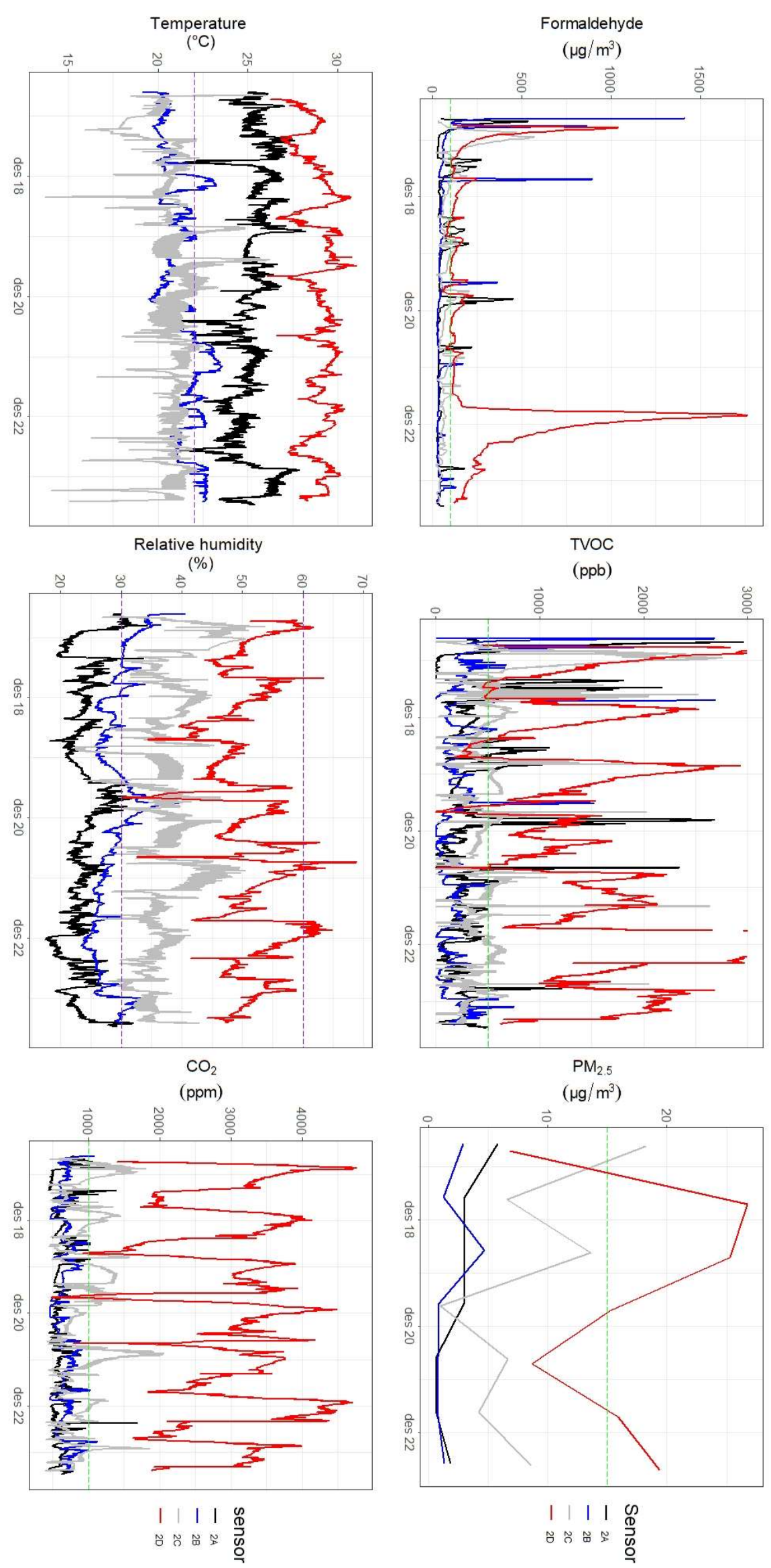

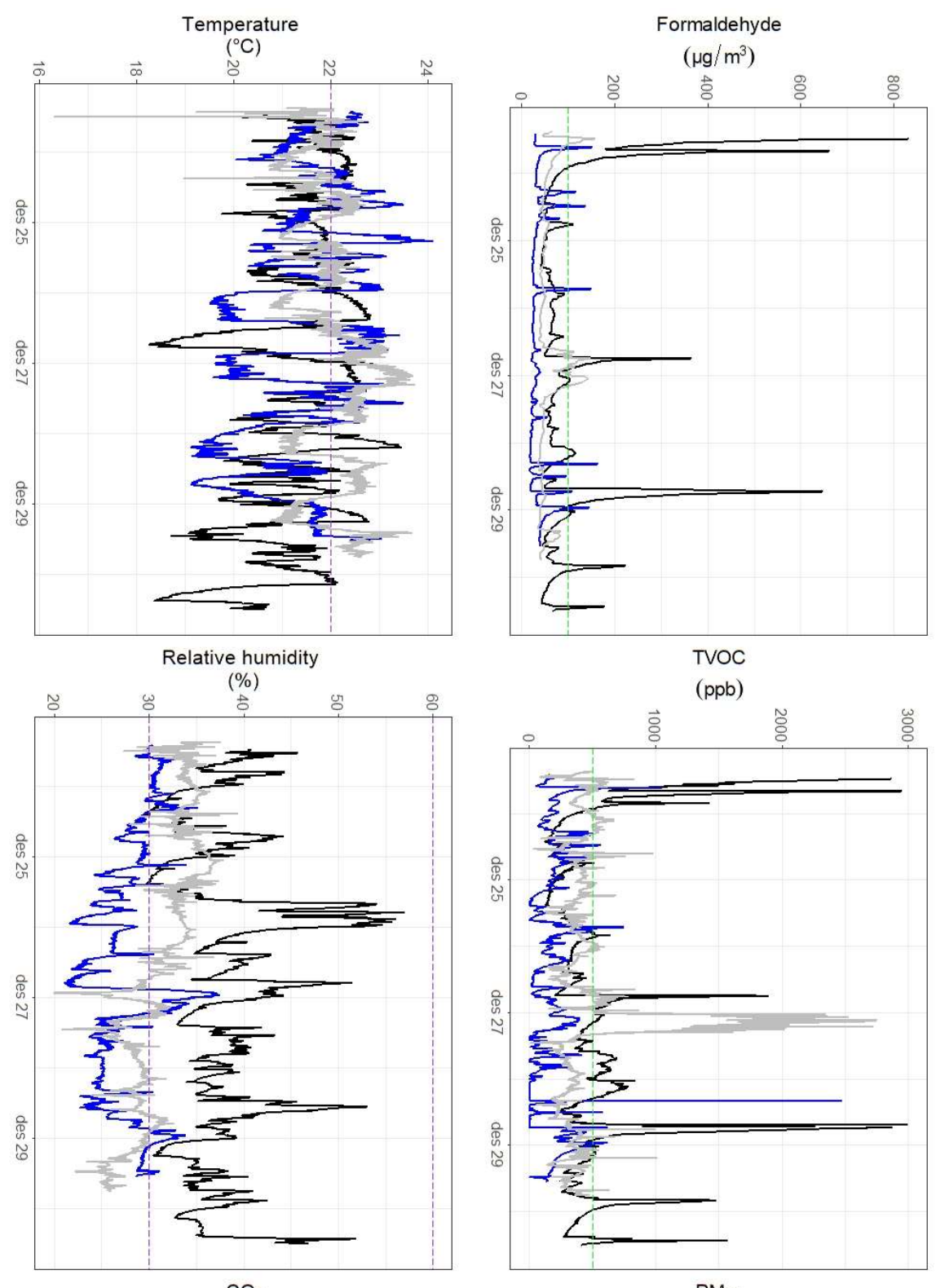

$\mathrm{CO}_{2}$

$\mathrm{PM}_{2.5}$

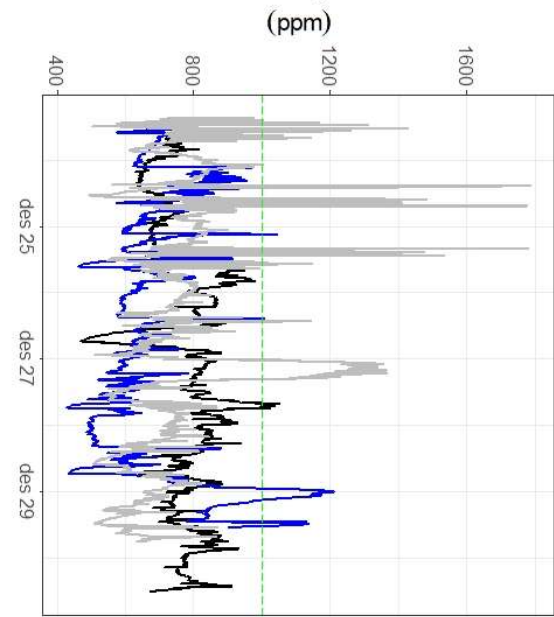

$\left(\mu \mathrm{g} / \mathrm{m}^{3}\right)$

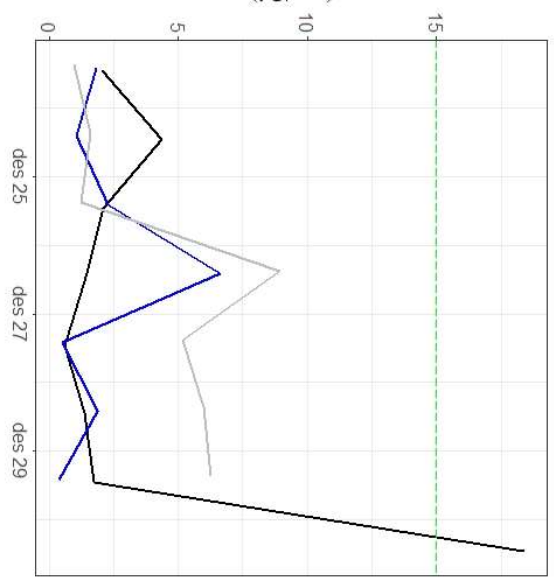

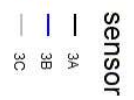

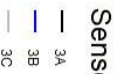


- According to the WELL Building Standard, the limit for TVOC is $<500 \mu \mathrm{g} / \mathrm{m}^{3}[9]$.

- For $\mathrm{PM}_{2.5}$ according to the NPHI, the maximum is $15 \mu \mathrm{g} / \mathrm{m}^{3}$ in daily averages [5].

- For temperature, the advised value that should not be overpass in heating season is $22{ }^{\circ} \mathrm{C}$ [4].

- For moisture, the advised range is $20-60 \%$ according to [10].

- For $\mathrm{CO}_{2}$ the advised limit is $1000 \mathrm{ppm}$ according to TEK10 [11].

Figure 2 shows the measurements in offices 1 A-D from December the $8^{\text {th }}$ to $16^{\text {th }}$. House $1 \mathrm{D}$ represents the newest and tightest envelope of all the measured home offices. In this house, there is mechanical ventilation supplying constant air. In this house the concentration of $\mathrm{CO}_{2}$ is mostly below $800 \mathrm{ppm}$ except for the evening of December $15^{\text {th }}$ when 8 people were using a lower room and thus, we see a peak in $\mathrm{CO}_{2}$ concentration. At the same time, this is the house with the highest supply of outdoor air and thus, the relative humidity is among the lowest. This house counts with heat recovery, electric heaters and a highly insulated envelope that keep the temperature constantly at $24{ }^{\circ} \mathrm{C}$ that the user has defined as comfort temperature. This house is also painted with low emitting materials and the concentrations of TVOC or formaldehyde are comparable with the other houses although the other houses have been painted several years before. It is very interesting to see that both $1 \mathrm{~A}$ and $1 \mathrm{D}$ had meetings when several people joined to cook Christmas cookies on the evening of December $13^{\text {th }}$ (also on $15^{\text {th }}$ of December) and both home offices present similar concentrations of formaldehyde and TVOC. However, the PM concentration differs much more. $1 \mathrm{~A}$ is placed very close to the kitchen and $1 \mathrm{D}$ is two floors away from the kitchen. Thus, the volatile and gaseous components dissolve in every room of the house but not the $\mathrm{PM}_{2.5}$ that has a much more local effect. $1 \mathrm{~B}$ and $1 \mathrm{C}$ are situated in the same building on the third and second floor. In 1B the user has an oil radiator that is turned on when the user is working, thus, the large variations during and outside working hours. In this room, there is a window in the roof and the user feels colder than when going to room $1 \mathrm{C}$ that is normally at a lower temperature. $1 \mathrm{C}$ is separated from the kitchen by a door that is normally closed. However, we can see the variations in the volatile compounds connected to cooking.

Figure 3 shows the measurements in home offices 2 (A-D) from $16^{\text {th }}$ to $23^{\text {rd }}$ of December. Here the measurements for home office 2D stand out. This is a 15 $\mathrm{m}^{2}$ sleeping room, office and kitchen where two adults and one baby live. During working hours one parent goes to work, the baby goes to kindergarten and the other parent stays at the home office. These users do not open the windows to ventilate to avoid the entrance of cold air (though the average temperature of the room is $28^{\circ} \mathrm{C}$ ). This affects the concentration of $\mathrm{CO}_{2}$ that in the worst moments is close to $5000 \mathrm{ppm}$. The users do not feel headaches but sometimes need to go for a walk "to get some air". These users are exposed to health affecting levels of formaldehyde, TVOC, $\mathrm{PM}_{2.5}$ and $\mathrm{CO}_{2}$ owing to surpassing the threshold levels defined by the World health organization and all national standards. Home office $2 \mathrm{~B}$ is placed in a basement at the top of a hill. This user always has the window closed and the 4.5 $\mathrm{m}^{2}$ room has no mechanical ventilation. However, the room's $\mathrm{CO}_{2}$ concentration is maintained below 1000 ppm. On windy days such as December $21^{\text {st }}$, the concentration of $\mathrm{CO}_{2}$ is lower. The building envelope has not been tightened though the windows were changed. During construction, the requirement of tightness for such a house was $4 \mathrm{~m}^{3} / \mathrm{m}^{3} \mathrm{~h}$ [12]. This may justify the low levels of $\mathrm{CO}_{2}$ together with a strong extraction in the bathroom. Home office $2 \mathrm{C}$ uses a wood stove additionally to an electric radiator, on the evening of the $16^{\text {th }}$ of December. On this day formaldehyde, TVOC and $\mathrm{PM}_{2.5}$ levels are much higher than for the other days probably related to wood firing. The users also report daily burning of candles in the evenings and this is reflected as peaks of TVOC and $\mathrm{PM}_{2.5}$ (though $\mathrm{PM}_{2.5}$ peaks are not visualized in Figure 3 as this graph represents 24-hours averages).

Figure 4 shows the measurements of home offices 3 (AC) from $23^{\text {rd }}$ to $30^{\text {th }}$ December 2020 (none of the users celebrated Christmas). $3 \mathrm{~A}$ is an office, living room, bedroom and kitchen space. As in all the other cases where there is a kitchen $(2 b, 2 c, 2 d, 3 a)$, we see an effect of cooking on the formaldehyde, TVOC and $\mathrm{PM}_{2.5}$ levels. Home office $3 \mathrm{C}$ is used also as a bedroom. On the $27^{\text {th }}$ of December, two people sleep and this influences $\mathrm{CO}_{2}$, relative humidity, temperature and TVOC that rise simultaneously. The user of this room also reports that on the first three days, the sensor was placed close to its face and this may justify the peaks in $\mathrm{CO}_{2}$, probably due to direct breathing on the sensor.

Figure 5 agglomerates the values for all the measured offices during working hours. Working hours are defined as between 8:00 at 16:00 and from Monday to Friday. In summary, the employees are exposed to the following concentrations:

Formaldehyde is over $100 \mu \mathrm{g} / \mathrm{m}^{3}$ more than $9 \%$ of the measured time. For the worst-case scenario, this value is surpassed $45 \%$ of the measured time.

For $\mathrm{PM}_{2.5}$ the cases where the measurements are over $15 \mu \mathrm{g} / \mathrm{m}^{3}$ represent only $4 \%$ of the time, though in the cases where there is an open kitchen in the same room, these values may rise to up to $26 \%$ of the time (note that we are looking at the 24-hours averages, large instantaneous peak happen frequently).

For the temperature, we have evaluated the hours outside the range from 20 to $24{ }^{\circ} \mathrm{C}$. When considering all the offices, the measured temperature is outside this range for $81 \%$ of the time, being the temperatures mostly over $24{ }^{\circ} \mathrm{C}$. In the worst case, the temperature is outside this range for $100 \%$ of the time. This proves that these users don't agree with the defined thermal comfort by the Norwegian TEK and regulate their heaters to feel comfortable. 

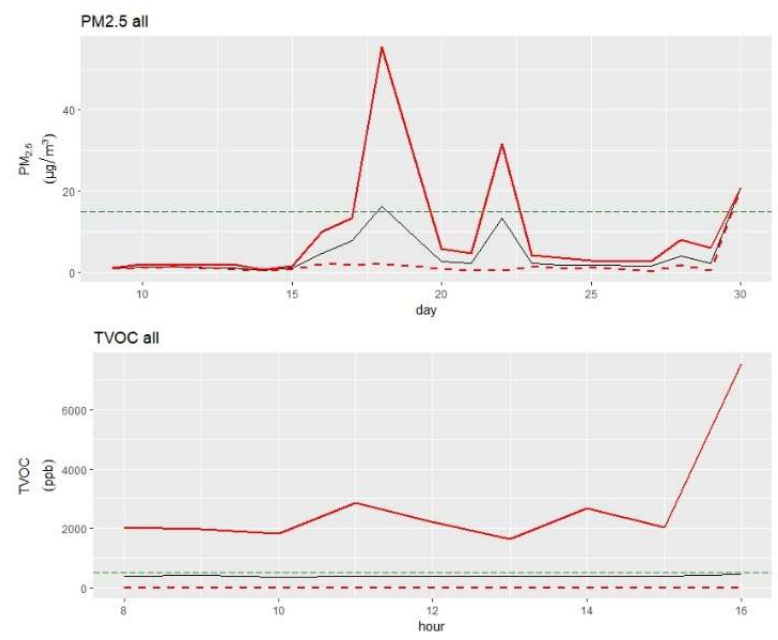

Figure 5. Aggregated values for all the home offices during working hours defined from 8-16 from Monday to Friday. $\mathrm{PM}_{2.5}$, formaldehyde and TVOC in $\mu \mathrm{g} / \mathrm{m}^{3}$ and $\mathrm{CO}_{2}$ in ppm The solid black line represents the average of all the measurements, the solid red line the maximum measured in that hour (or day for $\mathrm{PM}_{2.5}$ ), the dashed red represents the minimum measured in that hour (or day) and the green dashed line the health recommendation. For formaldehyde, the graph represents the 30 minutes averages and for $\mathrm{PM}_{2.5}$ the comparison is on daily basis.

For the relative humidity, the measured values are outside the range 30-60\% during $69 \%$ of the time, being the humidity below $20 \%$ during $8 \%$ of the time. This is a typical problem in Norwegian offices during winter as being the outdoor temperatures so low the indoor humidity is also very low. In the worst-case, the office $1 \mathrm{D}$ is below a humidity of $30 \% 100 \%$ of the time and below $20 \% 25 \%$ of the time. This user complains that since not working at the office, the contact lenses are stickier to the eyes.

Regarding TVOC, considering all the home offices, the value $500 \mu \mathrm{g} / \mathrm{m}^{3}$ is surpassed $18 \%$ of the time. The worst measured office this value is overpassed for $69 \%$ of the measured period.

Finally, the $\mathrm{CO}_{2}$ threshold of $1000 \mathrm{ppm}$ is surpassed $10 \%$ of the time considering all the home offices. However, for the worst measured home office, this value is never gone under.

We do not know how the home office affects their performance or health as this was not questioned.

\section{Discussion}

The levels of $\mathrm{PM}_{2.5}$ are generally very low in these measurements. Most of the sources for $\mathrm{PM}_{2.5}$ in these home offices are candle burning, wood stoves, oven cooking, the toasting of bread or outdoors. We did not measure the outdoor concentration of $\mathrm{PM}_{2.5}$ in each house, but Trondheim Municipality, the Norwegian Public Roads Administration and the Norwegian Institute for Air Research have installed measurement equipment not so far from the measured home offices. As Figure 6 shows with data from these sensors, during
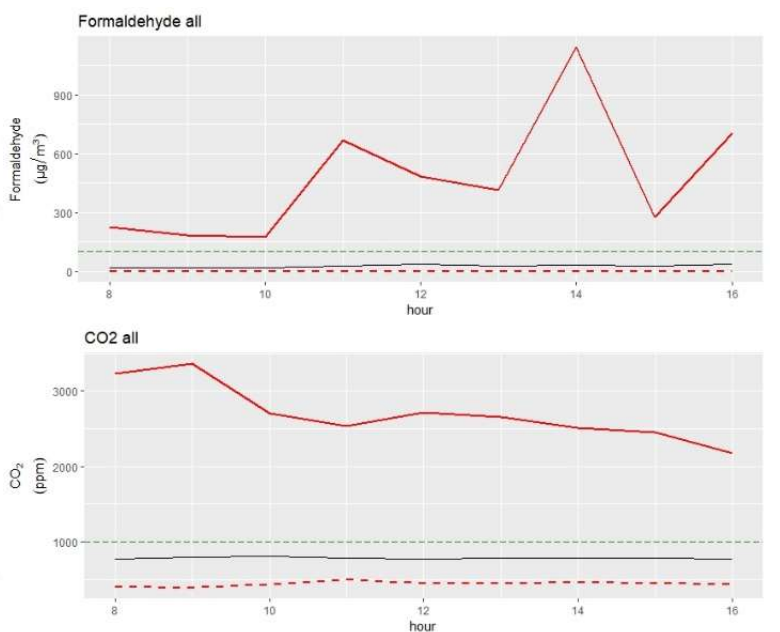

the measurements the average concentrations of $\mathrm{PM}_{2.5}$ are 3.4 and $5.4 \mu \mathrm{g} / \mathrm{m}^{3}$. Given that only $1 \mathrm{~A}$ and $2 \mathrm{C}$ use the wood stoves actively, most of the pollutants must derive from activities such as cooking and a candle burning. Still, the average values are generally lower than the $15 \mu \mathrm{g} / \mathrm{m}^{3}$ recommended.

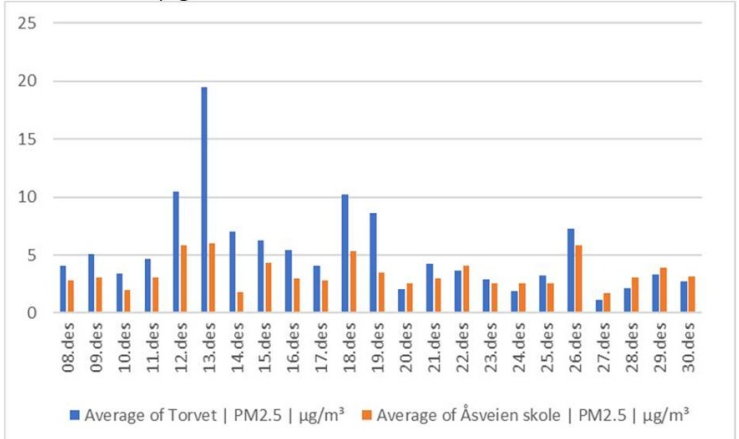

Figure 6. Hourly measurements of outdoor concentrations of PM2.5 in the vicinity of the home offices

The average value of formaldehyde is $60 \mu \mathrm{g} / \mathrm{m}^{3}$ for all the sensors during the measured period, but many home offices present peaks that should be addressed. Formaldehyde is probably emitted by furniture, wooden products, textiles, paints, glues, household cleaning products, beauty products, computers and electronic equipment and of course cooking, heating and candle and incense burning [8]. For many of these sources, the high temperature and high relative humidity affect the emissions [13], [14]. Some of the peaks of formaldehyde happen simultaneously to peaks in TVOC. The used sensors have known cross sensitivities with methanol, ethanol, isopropanol, carbon monoxide, phenol, acetaldehyde $\mathrm{H}_{2}, \mathrm{H}_{2} \mathrm{~S}$, and $\mathrm{SO}_{2}$. These may also affect the results. When asked many of the users responded that they had the habit to burn candles. Additionally, many of the home offices are close by or in the same room as the kitchen and temperatures are relatively high in many of the measured houses. Many users also report frequent use of antibacterial gels. Thus, high values can be sustained.

The TVOC average value is around $400 \mu \mathrm{g} / \mathrm{m}^{3}$ for all the home offices. However, the threshold value of 500 is often surpassed in many home offices. The 
sources for TVOC are many and it is difficult to remove them as TVOC are ubiquitous. For some wooden flooring, the emissions at $35{ }^{\circ} \mathrm{C}$ were more than double at $25^{\circ} \mathrm{C}$ [15].

Given that the home office has been for the last nine months and may continue in the future, more attention should be paid towards ventilating the formaldehyde and TVOC. The general advice for these pollutants would be to keep the temperatures low to remove emission from furniture, wooden products, textiles, etc and ventilate more.

For $\mathrm{CO}_{2}$ most of the users manage to keep its value below $1000 \mathrm{ppm}$, even when no employee had any indicator of its value, thus, for most of the home offices the ventilation was satisfactory regarding this parameter. However, for some home offices, the value was almost three to four times the threshold limit. When asked, most of the users claim to have the windows always closed and they rely on infiltration to ventilate away all pollutants. In cold periods like the measured, the infiltration levels must be high or very high. These house are not very airtight, thus these houses may be "very ventilated" but the ventilation is irregular and unpredictable.

Temperatures are regulated by the users to their comfort which is slightly higher than what is normally maintained in offices. The relative humidity is not controlled and just varies based on the occupant's activities. In general, most houses show RH close from the lowest advised threshold of $\mathrm{RH}$ and the outdoor temperatures are not even in the lowest of the year.

In general, while some parameters are generally kept below the thresholds for most of the offices, for some other parameters or in other offices, all the parameters, the measured values are dangerously high. The standard from the Norwegian Labour Inspection Authority should be updated to address the new needs that the home office is requiring, and the employers should remind employees to open windows more frequently to avoid health problems. Further measurements and correlations to health challenges are also recommended considering the results from this sample.

\section{Conclusions}

Measurements have been collected in eleven houses for at least one week in the last month of 2020. For many of the measured offices, thanks to the large infiltration rates, the general levels of $\mathrm{CO}_{2}$ are maintained below the threshold of $1000 \mathrm{ppm}$ and given the low outdoor pollution levels of Trondheim the $\mathrm{PM}_{2.5}$ levels are also quite low. However, for other pollutants such as TVOC or formaldehyde more ventilation would be advised as the lower the concentration of these, the better.

Comfort temperature when users can change it freely is higher than what is standard in offices. This should be further studied.

It is recommended that additionally to the ergonomic facilities, more recommendations of increasing the ventilation and/or open windows should be given from the employers to remember to keep the pollutants levels low.

This paper has been written within the Research Centre on Zero Emission Neighbourhoods in Smart Cities (FME ZEN). The authors gratefully acknowledge the support from the ZEN partners and the Research Council of Norway.

\section{References}

[1] Lovdata, "Lov om arbeidsmiljø, arbeidstid og stillingsvern mv. (arbeidsmiljøloven)," Arbeidsmiljøloven, 2016.

[2] NIPH, "Hjemmekontor og arbeidsplasser," 2020.

[3] T. N. L. I. Arbeidstilsynet, Forskrift om arbeid som utføres $i$ arbeidstakers, no. 4. 2007, pp. 35.

[4] DIBK, Byggteknisk forskrift (TEK17). 2017.

[5] T. Attramadal, P. Schwarze, and B. Rune, Anbefalte faglige normer for inneklima. Revisjon av kunnskapsgrunnlag og normer 2015. 2015.

[6] Arbeidstilsynet, Klima og luftkvalitet på arbeidsplassen, no. 444. 2012.

[7] M. Justo Alonso et al., "Performance assessment of a low-cost Arduinos-based sensor station," 2021.

[8] WHO, "Guidelines for indoor air quality Selected Pollutants," WHO Guidel., vol. 9, p. 454, 2010.

[9] International WELL Building Institute, "The WELL Building Standard V2.0," The next version of the WELL Building Standard, 2018.

[10] FHI, "Temperatur, fukt og trekk er viktig for kroppens varmebalanse," 2015.

[11] DIBK, "Byggteknisk forskrift (TEK 10)," 2010.

[12] P. Blom and O. G. Sivert, Bygg tett! 2012.

[13] F. Haghighat and L. De Bellis, "Material emission rates : Literature review, and the impact of indoor air temperature and relative humidity," Build. Environ., 1998.

[14] P. Wolkoff and S. K. Kjærgaard, "The dichotomy of relative humidity on indoor air quality," Environment International. 2007.

[15] Y. K. Lee and H. J. Kim, "The effect of temperature on VOCs and carbonyl compounds emission from wooden flooring by thermal extractor test method," Build. Environ., 2012. 